\title{
The Guidelines for Modelling the Preloading Bolts in the Structural Connection Using Finite Element Methods
}

\author{
Paulina Krolo, Davor Grandić, and Mladen Bulić \\ Department of Structural Engineering and Technical Mechanics, Faculty of Civil Engineering, University of Rijeka, \\ Radmile Matejčić 3, 51000 Rijeka, Croatia
}

Correspondence should be addressed to Paulina Krolo; paulina.krolo@uniri.hr

Received 30 March 2016; Revised 25 May 2016; Accepted 29 May 2016

Academic Editor: Marek Krawczuk

Copyright (C) 2016 Paulina Krolo et al. This is an open access article distributed under the Creative Commons Attribution License, which permits unrestricted use, distribution, and reproduction in any medium, provided the original work is properly cited.

The aim of this paper is the development of the two different numerical techniques for the preloading of bolts by the finite element method using the software Abaqus Standard. Furthermore, this paper gave detailed guidelines for modelling contact, method for solving the numerical error problems such as numerical singularity error and negative eigenvalues due to rigid body motion or the problem of the extensive elongation of bolts after pretension which is occurring during the analysis. The behaviour of bolted joints depending on the two different approaches of pretension was shown on the example of an extended end-plate bolted beamto-column connection under the monotonic loading. The behaviour of beam-to-column connection was shown in the form and moment-rotation $(M-\phi)$ curves and validated by experimental test. Advantages and disadvantages of pretension techniques, as well as the speed of numerical models, were also presented in this paper.

\section{Introduction}

The bolted joints remain the most common connection method in the construction and machine design. As a structural component, it is often considered the critical part of an assembly. Due to the high cost of experimental test, development of the computer programs, especially the finite element modelling, gives accurate prediction of the real behaviour of such type of joints.

There are a lot of articles [1-7] which analyzed the behaviour of the assembly with bolted joints. It takes into account the preload bolts in the joint. Maggi et al. [2] use the temperature gradient in the bolts to impose the pretension force. Guidelines for modelling the bolt load are available in Abaqus [8], using the bolt load method and the adjust length method.

The numerical problems such as numerical singularity error, negative eigenvalues, rigid body motion, and problem of the extensive elongation of bolts after pretension are very often during the numerical analysis. All of these problems may stop the procedure or give the inaccurate results of the analysis. Contact surfaces with edges or corners also may create the convergence difficulties. Sharp corners may produce the element distortion and high stress level in the contact zones. Selamet and Garlock [9] give the solution for edges and corner numerical problems, as well as the comparison of explicit and implicit solution techniques.

Two different approaches to preloading of the bolts will be presented at the first part of the paper. The first technique was standardized in Abaqus software and uses bolt load for preloading. During the numerical analysis, using standardized Abaqus technique of preloading, all of the aforementioned numerical problems may occur. In order to avoid these numerical errors, the second technique of preloading will be presented which uses the initial stress. The comparison between these preloading techniques will be shown on the example of an extended end-plate bolted beam-to-column connection. Results obtained from numerical analysis will be compared with experimental test according to [10].

\section{Finite Element Model of Bolted Joints}

Numerical modelling of bolted joints is carried out by using the following parameters: geometric and material nonlinearities of the elementary parts of the joints, bolt pretension force, contact between connected plates, washers and plated elements, bolt-shank and hole, and friction. The nut and the bolt-head were considered as a single body with bolt-shank 


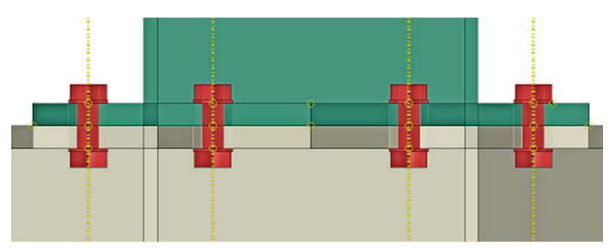

Figure 1: Bolted joint.

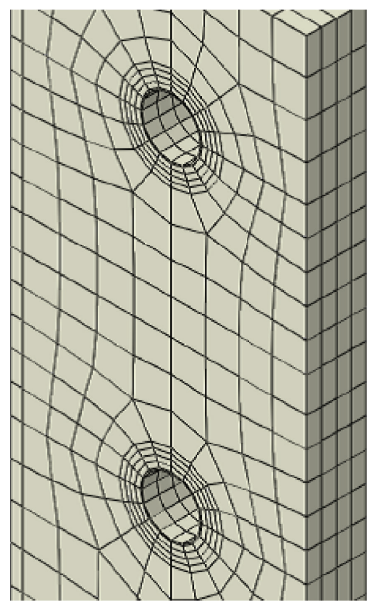

(a)

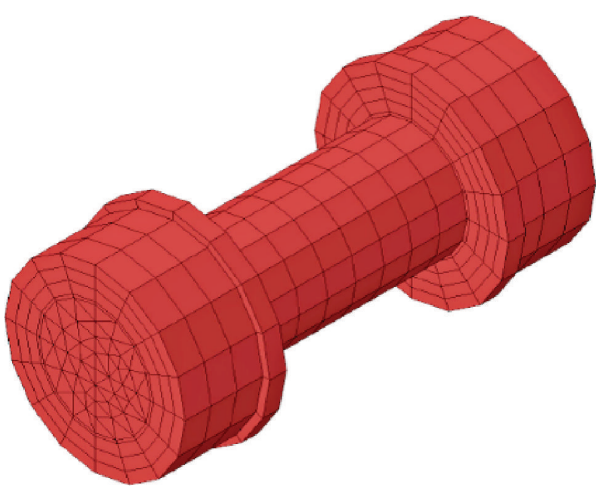

(b)

FIGURE 2: Finite element model of (a) plate element; (b) bolt.

together with washers on both ends of the bolt. Threaded part of the bolt-shank and the extended length of the bolt beyond each nut were ignored. Hexagonal shape of the bolt-head and nut was replaced with a cylinder. The typical bolted joint is presented in Figure 1.

2.1. Finite Element Mesh and Contact Modelling. The plated elements in the joint were meshed with 8-node first-order (linear) hexagon (brick) elements with incompatible modes (C3D8I). Each of these elements has 13 additional degrees of freedom (DOF) when compared to the fully integrated elements (C3D8), providing superior performance in bending dominant problems without shear locking behaviour or zero energy deformation modes; see Figure 2(a). The 6-nodded linear triangular prism element (C3D6) was used to model the bolts. The details of the finite element mesh are shown in Figure 2(b). Structure mesh technique is used for all parts of assembly. Previously, the bolts as well as bolt-hole region are quarter-partitioned. Then, they mesh with 16 elements around the circumference.

Numerical results are highly sensitive to the contact properties between components of the joints and the preloaded bolts. Small sliding surface-to-surface discretization method was considered for all the contacts. The surface contact properties between the plate elements were modelled as a tangential behaviour using penalty friction with the friction coefficient value of 0.44 . Normal behaviour contact properties using Augmented Lagrangian Formulation were considered for the normal forces between the same components; see Figures 3(a) and 3(b). The tangential contact between bolt-shank and bolt-hole was considered to be frictionless; see Figures 3(c) and 3(d). The hard contact was used for the connection between bolt-head/nut and plate elements. The bolts are usually more rigid than hot-rolled steel member, and they are usually denoted as a master surface in the contact pairs; see Figure 4.

2.2. Simulation Procedure and Bolt Preload. The analysis has been performed through the steps in two different ways depending on the type of the bolt pretension technique.

Analysis Procedure 1 (“bolt load” preloading technique)

Initial Step. Boundary condition.

Step 1. Bolt preloading/activating the contact element.

Step 2. Fixing the bolt length.

Step 3. External load.

The bolts are preloaded in the first step of the analysis according to bolt load method. The pretension is simulated 


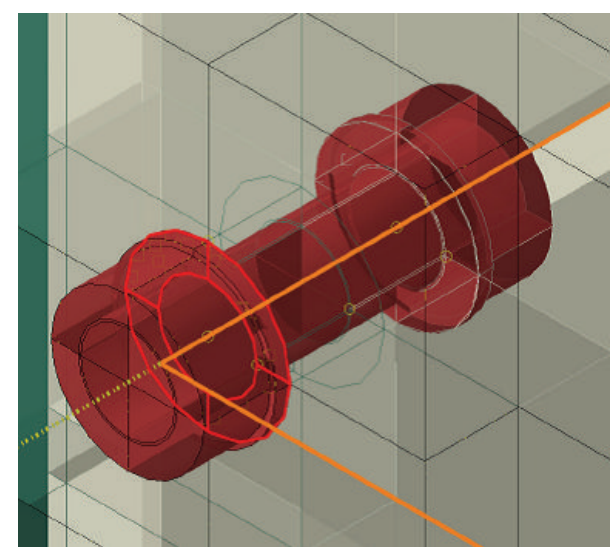

(a)

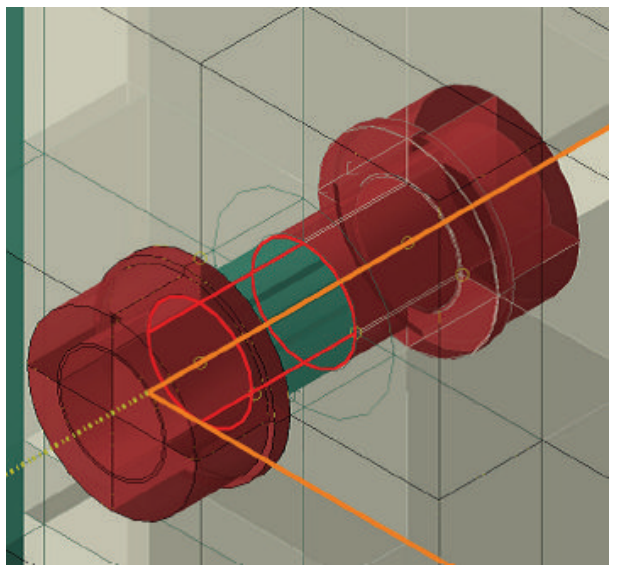

(c)

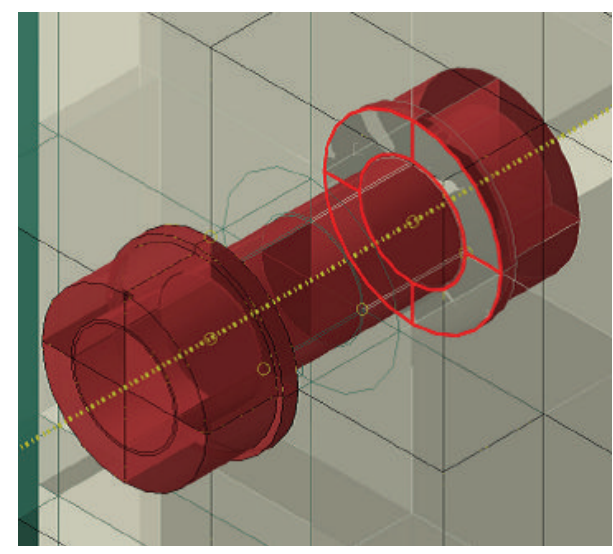

(b)

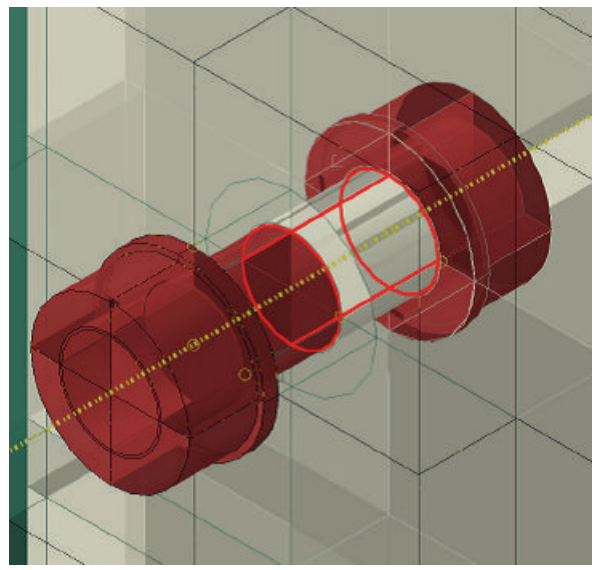

(d)

Figure 3: Contact between bolt and plate elements: (a) and (b) are friction and "hard" contact, and (c) and (d) are frictionless.

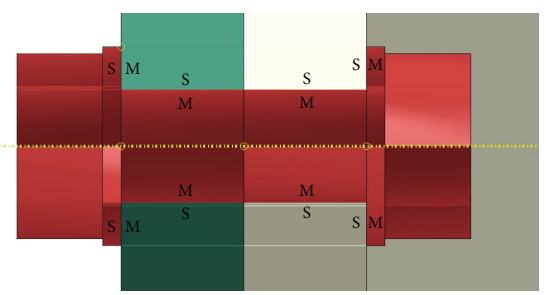

FIGURE 4: Definition of master and slave surface in the contact zones. M: master surface; S: slave surface.

by splitting the bolt body and applying a magnitude of preload force on two parallel surfaces in the bolt-shank. At Abaqus/CAE are created the datum axes and the partition of the bolt body in the middle of the shank as shown in Figure 5. The magnitude of preload force is $70 \%$ of their minimum tensile strength of the bolt [11]. After applying the pretension to the bolts, their length is fixed at their current position. This technique helps to avoid the problem with extensive elongation of the bolts under the loading. During the first two steps (Initial Step and Step 1), all three translational degrees of freedom (DOF) at the section of pretension are restrained. This degree of freedom served as the artificial boundary condition to prevent the numerical singularity error which occurs as a result of rigid body motion. After the preloading and activating the contact properties, this artificial boundary condition is then removed.

Analysis Procedure 2 ("initial stress" preloading technique)

Initial Step. Boundary condition and initial state of stress in bolt-shank.

Step 1. Activating the contact element with small load value.

Step 2. External load.

The preloading of bolt is simulated in the Initial Step as initial state of stress in the bolt-shank which is defined in the load module as a Predefined Field. In order to activate the 


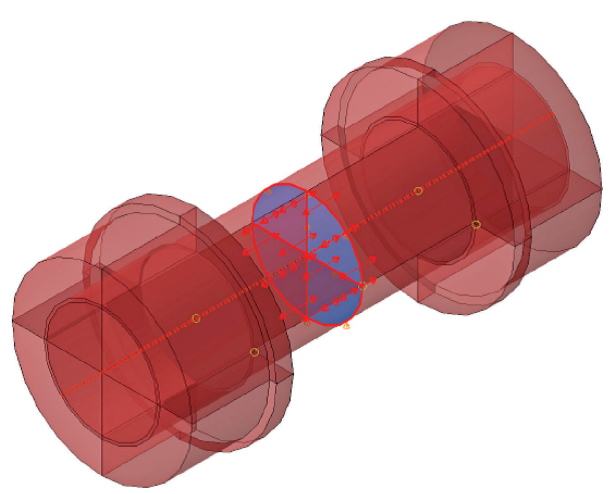

Figure 5: Preload bolt by bolt load method.

contact between connected elements, small loading will be acting on the element in the direction of pretension. The value of this load is small enough that it does not have an effect on the overall behaviour of joint.

Comparison between aforementioned analysis procedures will be shown on the numerical model of extended endplate connection under the monotonic loading. The accuracy of obtaining results will be compared with experimental test SC3 by [10]. Advantages and disadvantages of pretension technique, as well as the speed of numerical models, will be presented in the next section.

\section{Finite Element Analysis of Extended Beam-to-Column Bolted Connection}

The extended end-plate connection consists of steel H-shaped beam H-300 $\times 200 \times 8 \times 12 \mathrm{~mm}$, H-shaped column $\mathrm{H}-300 \times$ $250 \times 8 \times 12 \mathrm{~mm}$, and high-strength pretensioned bolts; endplate thickness was $20 \mathrm{~mm}$, and column stiffeners thickness was $12 \mathrm{~mm}$. The specimen was fabricated from Q345B steel. The end-plate was connected to the column flange with highstrength pretensioned bolts M20 with diameter $20 \mathrm{~mm}$ and grade 10.9. The pretension force value was $155 \mathrm{kN}$ according to Chinese Specification JGJ82-91 (1992). The friction coefficient of contact surface was considered as 0.44 . Loading pattern was imposed on the end of the beam as shown in Figure 6. The thickness of the column flange is taken to be the same as the thickness of the end-plate, within the length range of $100 \mathrm{~mm}$ above the extension of the end-plate and $100 \mathrm{~mm}$ below the extension of the end-plate.

In the finite element model, the stress-strain relationship of steel plates is elastic-perfectly plastic trilinear and Poisson's ratio is 0.3 . Yield strength and ultimate strength value of steel plates thicker than $16 \mathrm{~mm}$ are $363 \mathrm{MPa}$ and $537 \mathrm{MPa}$, respectively, while its Young modulus is $204227 \mathrm{MPa}$. Yield strength and ultimate strength value of steel plates thinner than or equal to $16 \mathrm{~mm}$ are $391 \mathrm{MPa}$ and $559 \mathrm{MPa}$, respectively, while its Young modulus is $190707 \mathrm{MPa}$. The stress-strain relationship of high-strength bolts is trilinear and material properties are shown in Table 1. Young's modulus of the bolts is taken as $206000 \mathrm{Mpa}$. The stress-strain relationship was shown in Figure 7.
TABLE 1: Material properties of high strength bolts.

\begin{tabular}{lccc}
\hline Stress $[\mathrm{MPa}]$ & 990 & 1160 & 1160 \\
\hline Strain & 0.00483 & 0.136 & 0.15 \\
\hline
\end{tabular}

Due to the symmetry about a vertical plane passing through the beam and column webs, only one-half of the connection is considered in the numerical model; see Figure 8. Numerical modelling of connection is carried out by using the following parameters: geometric and material nonlinearities of the elementary parts of connection, bolt pretension force, contact between column flange and end-plate, washers and plated elements, bolt-shank and hole, and friction. Static analysis was conducted for the monotonic loading as displacement control load with value of $125 \mathrm{~mm}$ which was acting on the beam end at the lever arm of $1200 \mathrm{~mm}$ (distance from the loading point to the column flange). The constant axial force with a value of $485 \mathrm{kN}$ was acting on the top and the bottom end of the column. Axial force was modelled as the pressure preentire surface of the cross section.

\section{Results and Discussions}

In order to validate the accuracy of nonlinear finite element model of end-plate connection, obtained results are compared with experimental test by Shi et al. [10]. The behaviour of beam-to-column connection was shown in the form of moment-rotation $(M-\phi)$ curves; see Figure 9. Red curve represents the results of model obtained from analysis with "bolt load" preloading technique, while the green curve represents the results of model obtained from analysis with "initial stress" preload technique. Both curves were comparable with a black curve, which present the experiment test results. Loading capacity and moment resistance of connection were shown in Table 2.

State of stress after pretension of the bolt using "bolt load" technique is shown in Figure 10. Stress value in the preloading direction before the external loading was 497.27 $\mathrm{MPa}$; see Figure 11. Figure 12(a) presents the initial stress on the first frame of the analysis and had a value $840 \mathrm{MPa}$. After activating the contact properties between the connected elements, redistribution of stresses was occurring between the bolt and 


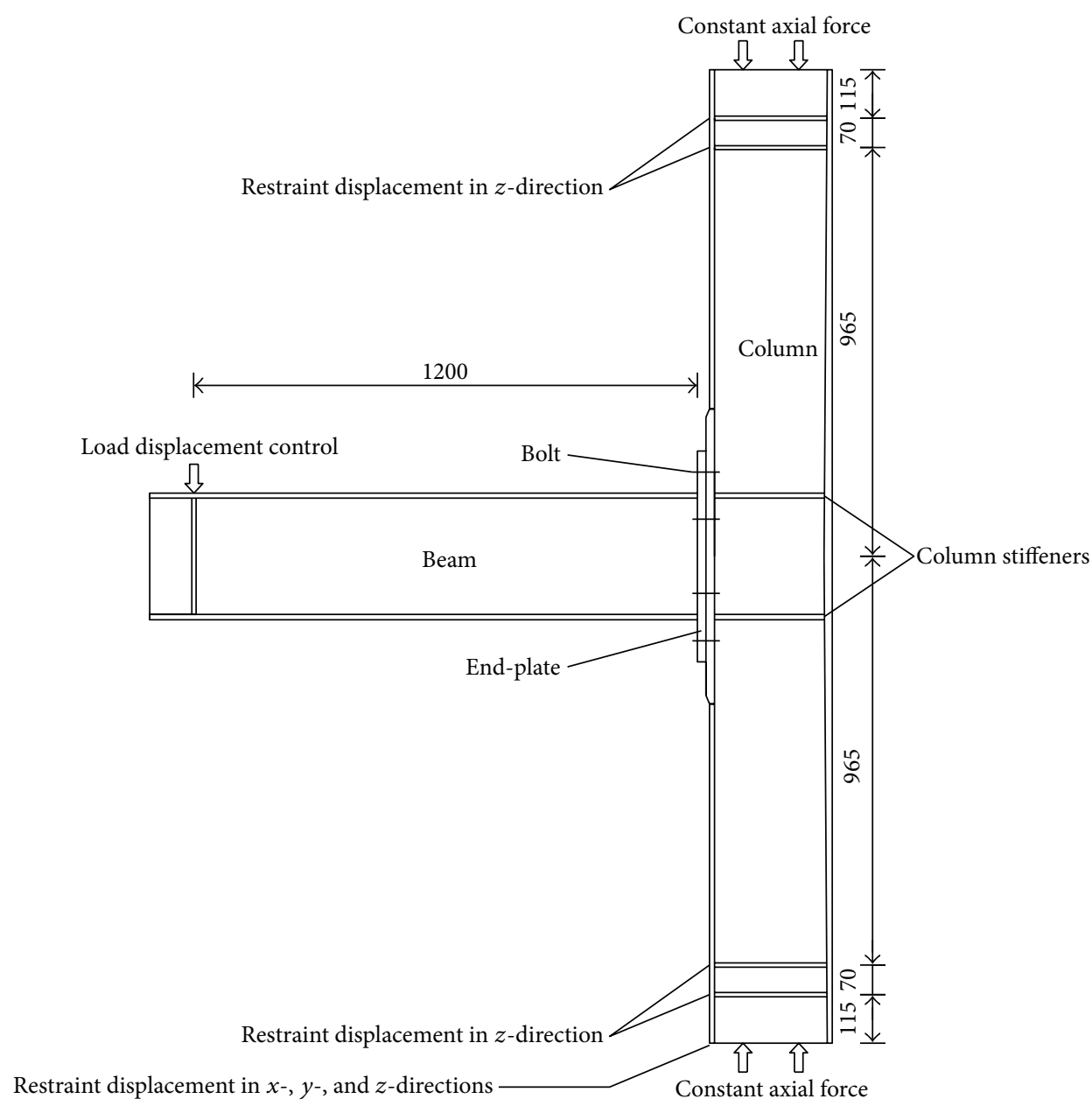

Figure 6: Details of end-plate beam-to-column connection (mm).

TABLE 2: Comparison of numerical and test results.

\begin{tabular}{lcccc}
\hline & & FEA & \multicolumn{2}{c}{ Test by Shi et al. [10] } \\
& Loading capacity $[\mathrm{kN}]$ & Moment resistance $[\mathrm{kNm}]$ & Loading capacity $[\mathrm{kN}]$ & Moment resistance $[\mathrm{kNm}]$ \\
\hline "Bolt load" case & 256.89 & 308.28 & 256.9 & 308.3 \\
"Initial stress" case & 244.84 & 303.42 & 2 & \\
\hline
\end{tabular}

plate elements. Finally, the stress value in the bolt was 494.6 MPa.

Figure 12(a) shows the failure modes of finite element model and Figure 12(b) failure modes of the specimen SC3 which is experimentally tested by Shi et al. [10]. Figure 12(b) shows the failure mode after bolt fracture.

\section{Conclusions}

The behaviour of preload bolted joints was investigated for two different techniques of preloading using finite element method in software Abaqus Standard. The behaviour of bolted joints was shown on the extended beam-to-column end-plate connection whose results were then compared with experimental test. The static analysis for "bolt load" preloading technique model gives the nonsignificant difference of the loading capacity value compared with test results. The static analysis for "initial stress" preloading technique model gives $4,92 \%$ lower value of the loading capacity compared with test results. If the loading process was continued, the higher loading capacity was obtained, showing the interrupted part of the curve in Figure 9. Such behaviour is the result of the simple constitutive model of steel which is used in the finite element model. In spite of that, both numerical results provide very good behaviour of the connection until achieving the maximum moment resistance compared with experimental test. Finally, the finite element method is a cost-effective way to investigate and provide the satisfactory prediction of the behaviour of connection.

Comparing the "bolt load" and "initial stress" preloading technique, the results show that the "initial stress" preloading technique gives satisfactory results. This method also avoids 


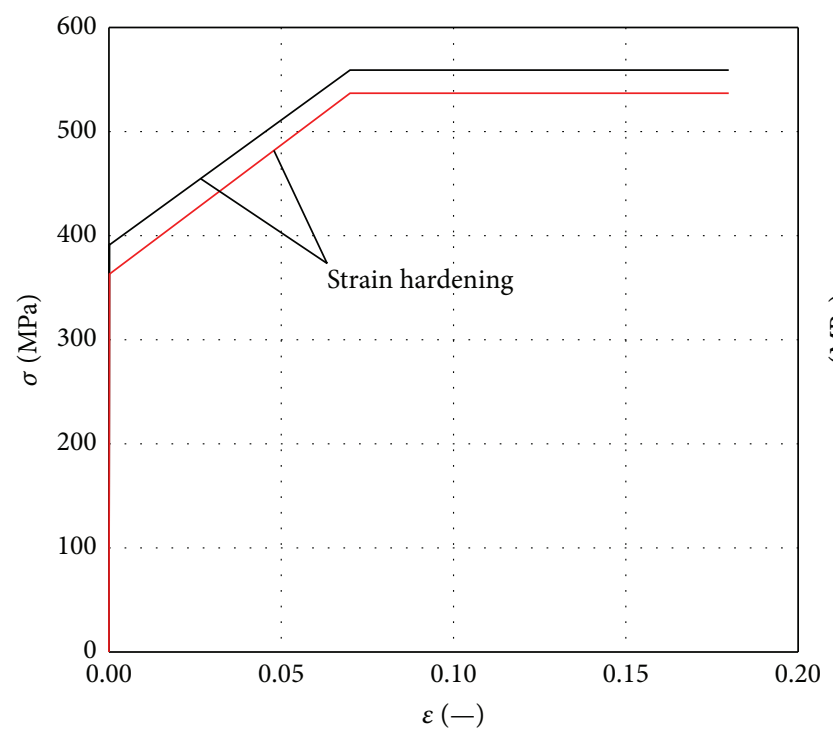

- Steel plates $t \leq 16 \mathrm{~mm}$ - Steel plates $t>16 \mathrm{~mm}^{\prime \prime}$

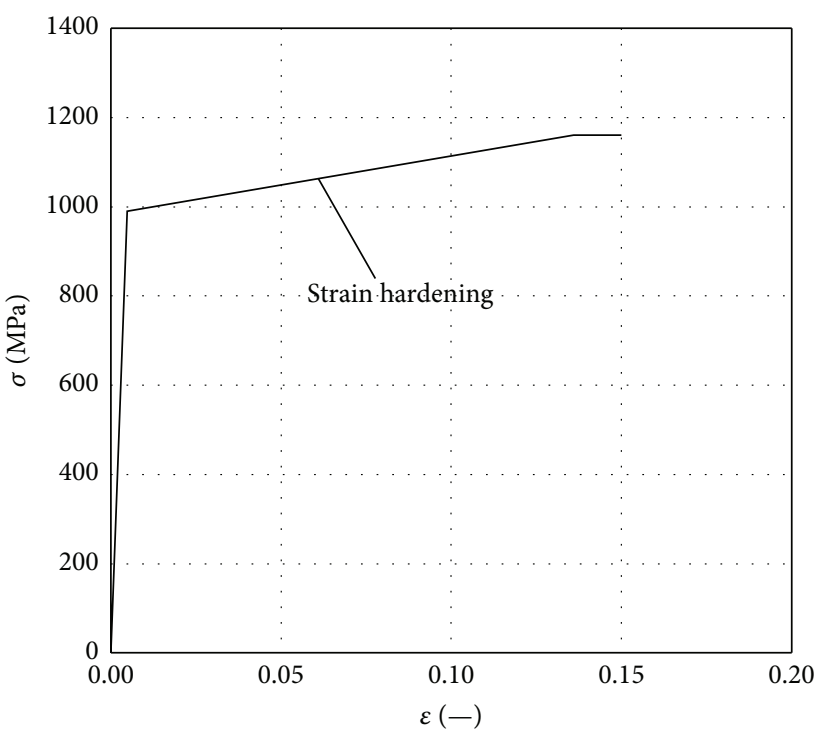

- Bolts

FIGURE 7: Stress-strain relationship of steel plates and bolts.

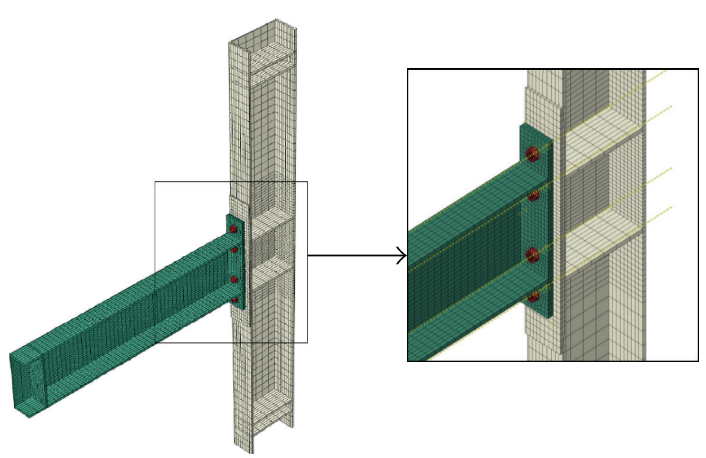

Figure 8: Finite element model of connection.
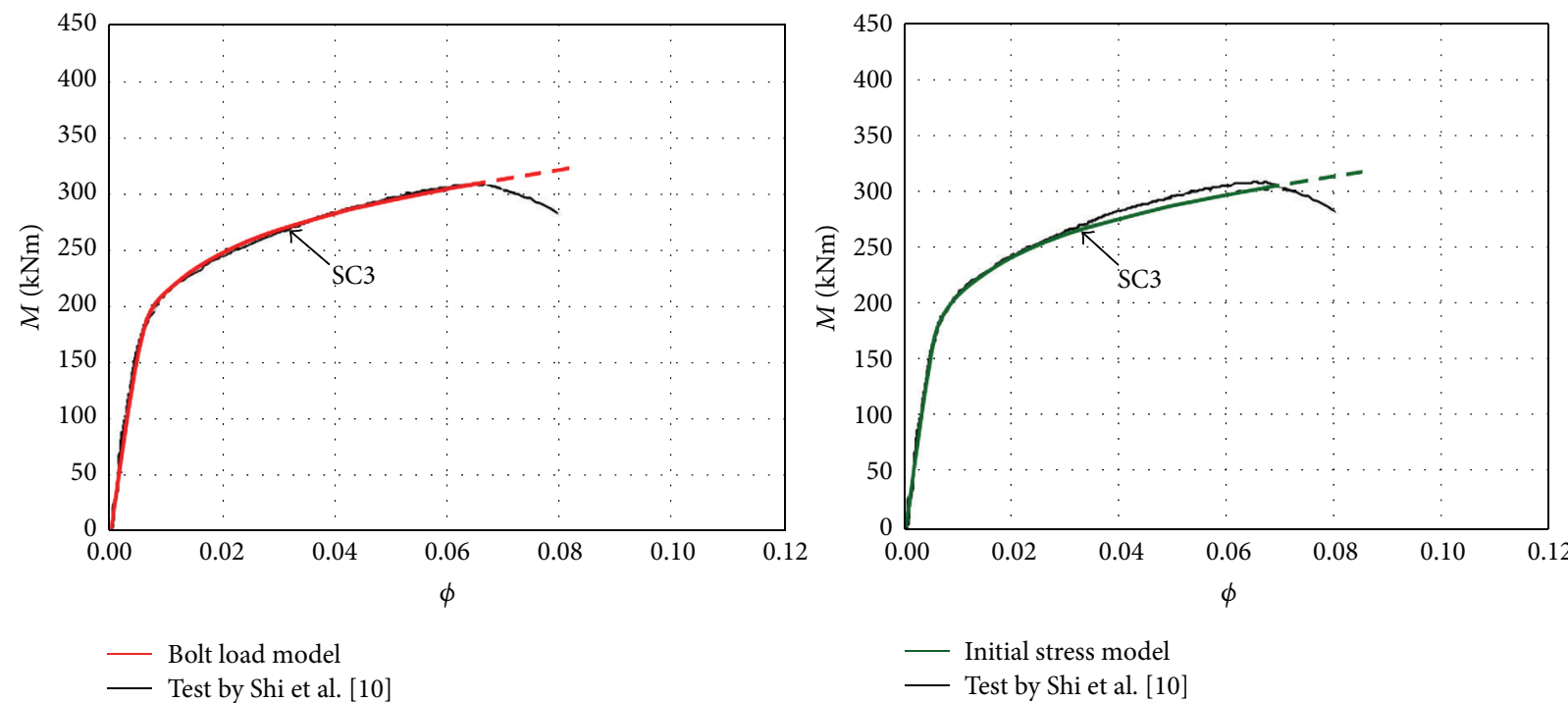

Figure 9: Moment-rotation curve $(M-\phi)$. 


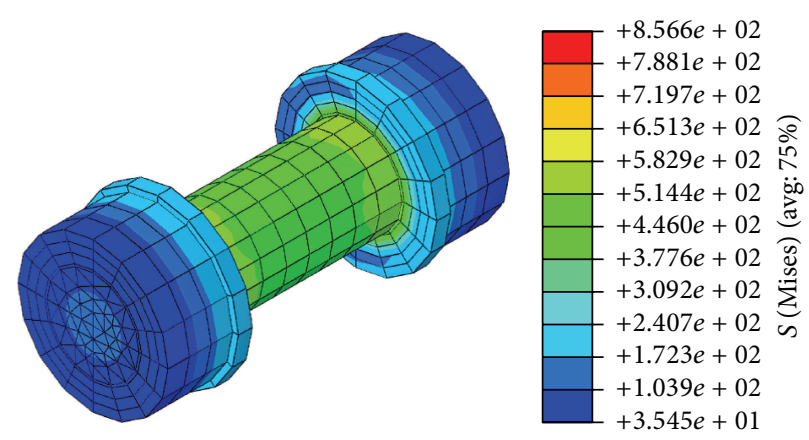

Figure 10: Preload bolt by "bolt load" preloading technique.

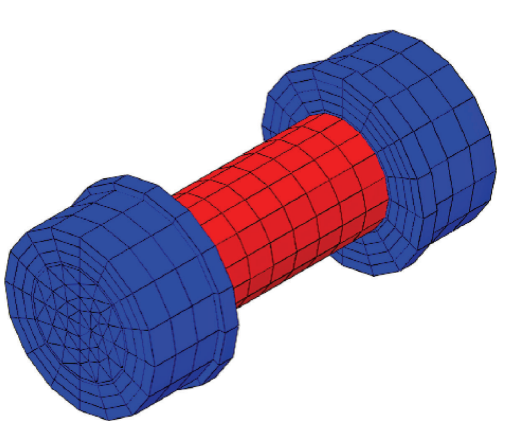

(a)

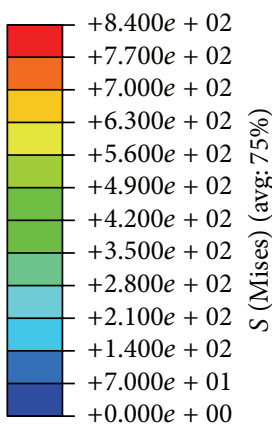

$+7.000 e+01$
$+0.000 e+00$

FIGURE 11: Preload bolt by “initial stress” preloading technique.

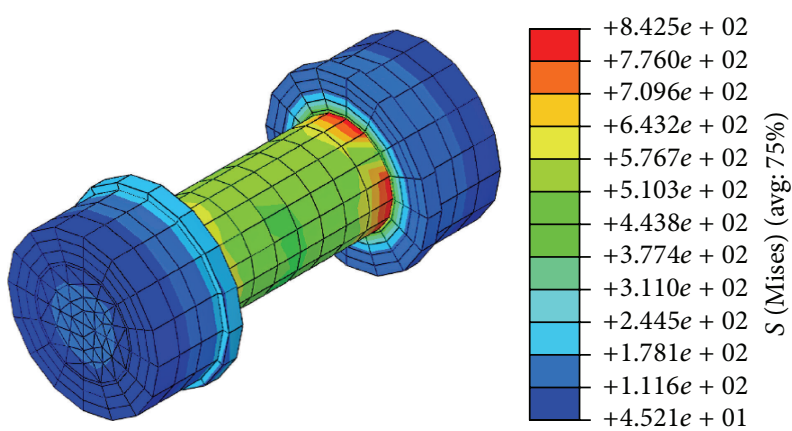

(b)

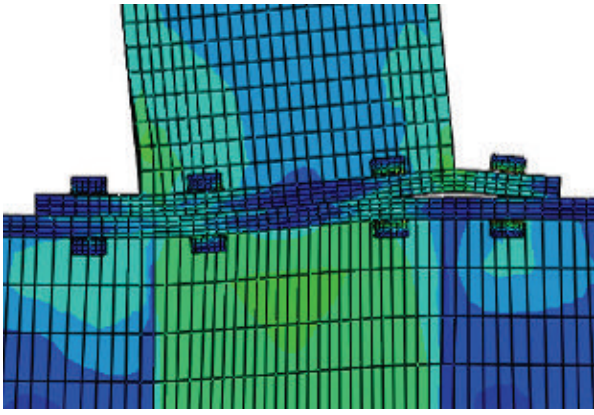

(a)

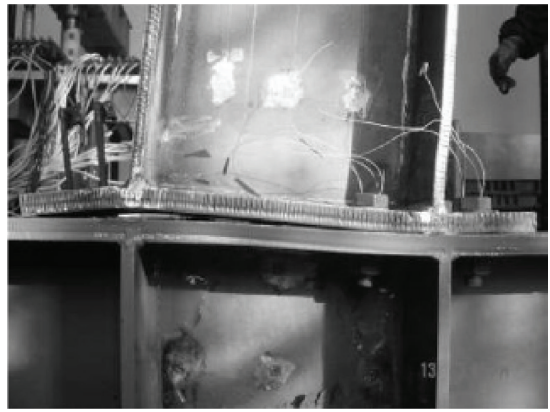

(b)

FIGURE 12: Failure mode of (a) finite element model and (b) specimen by Shi et al. [10].

the numerical error problems such as numerical singularity and negative eigenvalues as the results of rigid body motion. Using this method of preloading in the connection, the artificial boundary condition before preloading is not necessary. In addition, problem of extensive elongation of bolts due to external load is also avoided. Moreover, the model with "bolt load" preloading technique completes the analysis with 34 increments while the model with "initial stress" preloading technique has only 23 increments. This computational efficiency plays an important role when the models are larger with more contact surfaces.

\section{Competing Interests}

The authors declare that there are no competing interests regarding the publication of this paper.

\section{Acknowledgments}

The research presented in this work was done within the scientific project, Grant no. 13.05.1.1.01 supported by the University of Rijeka. 


\section{References}

[1] M. R. Bahaari and A. N. Sherbourne, "Behavior of eight-bolt large capacity endplate connections," Computers and Structures, vol. 77, no. 3, pp. 315-325, 2000.

[2] Y. I. Maggi, R. M. Gonçalves, R. T. Leon, and L. F. L. Ribeiro, "Parametric analysis of steel bolted end plate connections using finite element modeling," Journal of Constructional Steel Research, vol. 61, no. 5, pp. 689-708, 2005.

[3] C. Díaz, M. Victoria, P. Martí, and O. M. Querin, "FE model of beam-to-column extended end-plate joints," Journal of Constructional Steel Research, vol. 67, no. 10, pp. 1578-1590, 2011.

[4] G. Shi, Y. Shi, Y. Wang, and M. A. Bradford, "Numerical simulation of steel pretensioned bolted end-plate connections of different types and details," Engineering Structures, vol. 30, no. 10, pp. 2677-2686, 2008.

[5] M. Gerami, H. Saberi, V. Saberi, and A. S. Daryan, "Cyclic behavior of bolted connections with different arrangement of bolts," Journal of Constructional Steel Research, vol. 67, no. 4, pp. 690-705, 2011.

[6] M. Wang, Y. Shi, Y. Wang, and G. Shi, "Numerical study on seismic behaviors of steel frame end-plate connections," Journal of Constructional Steel Research, vol. 90, pp. 140-152, 2013.

[7] R. Kiamanesh, A. Abolmaali, and M. Razavi, "Effect of circular bolt pattern on behavior of extended end-plate connection," Journal of Structural Engineering, vol. 139, no. 11, pp. 1833-1841, 2013.

[8] ABAQUS, Analysis User's Manual I_V, Version 6.12, ABAQUS, Dassault Systèmes, Fremont, Calif, USA, 2012.

[9] S. Selamet and M. Garlock, "Guidlines for modeling three dimensional structural conncetion models using finite element methods," in Proceedings of the International Symposium on Steel Structures: Culture \& Sustainability, p. 14, Istanbul, Turkey, September 2010.

[10] G. Shi, Y. Shi, Y. Wang, and F. Bijlaard, "Monotonic loading tests on semi-rigid end-plate connections with welded I-shaped columns and beams," Advances in Structural Engineering, vol. 13, no. 2, pp. 215-229, 2010.

[11] EC3, Design of Steel Structures, Part 1-8: Design of Joints (EN 1993-1-8), European Committee for Standardization (CEN), Brusseles, Belgium, 2005. 


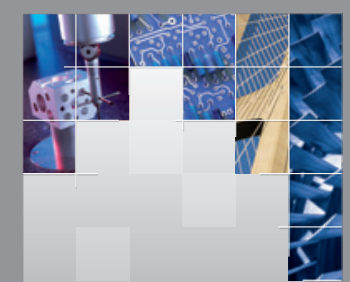

\section{Enfincering}
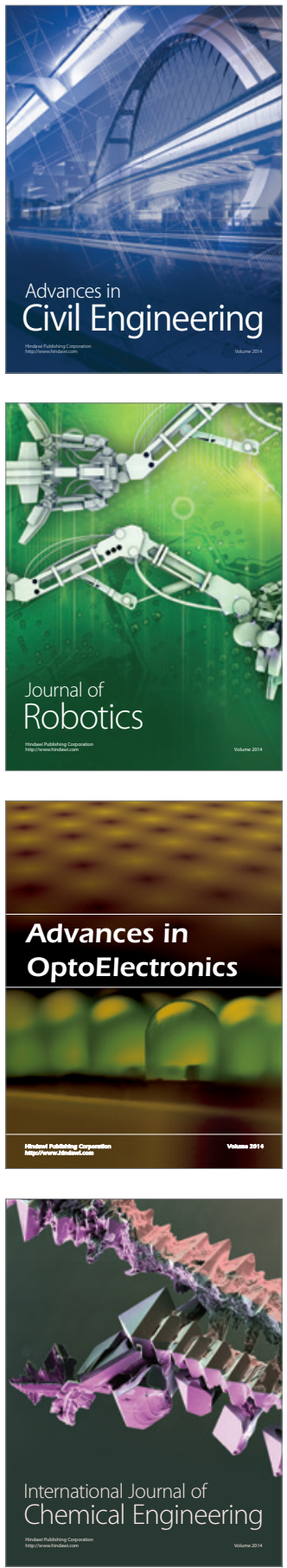

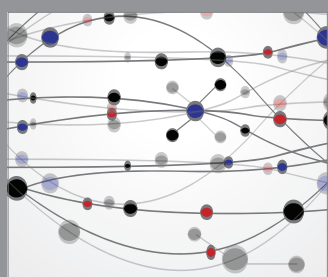

The Scientific World Journal

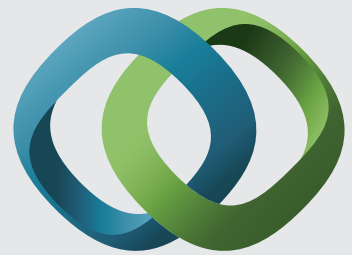

\section{Hindawi}

Submit your manuscripts at

http://www.hindawi.com
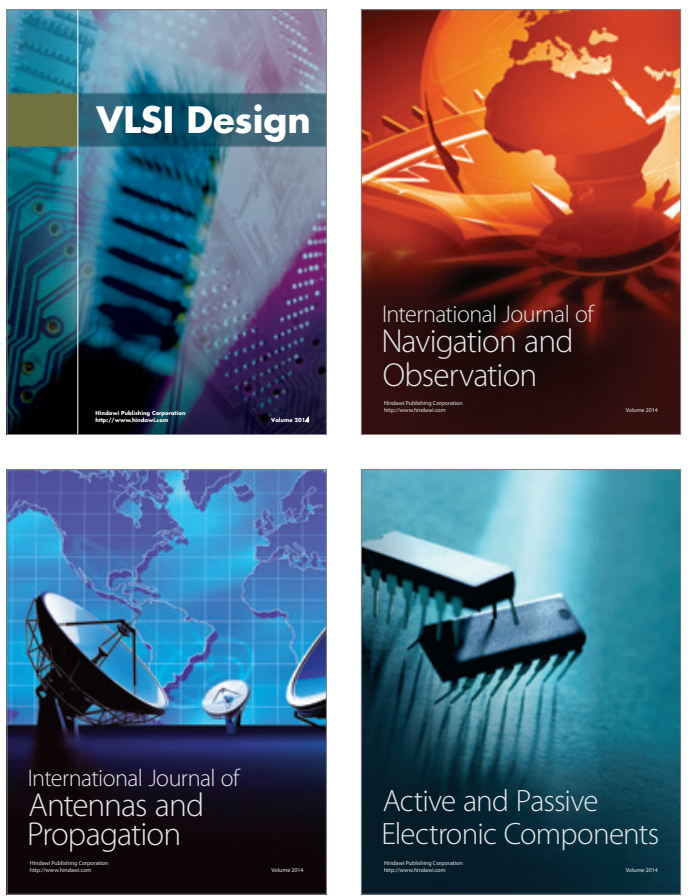
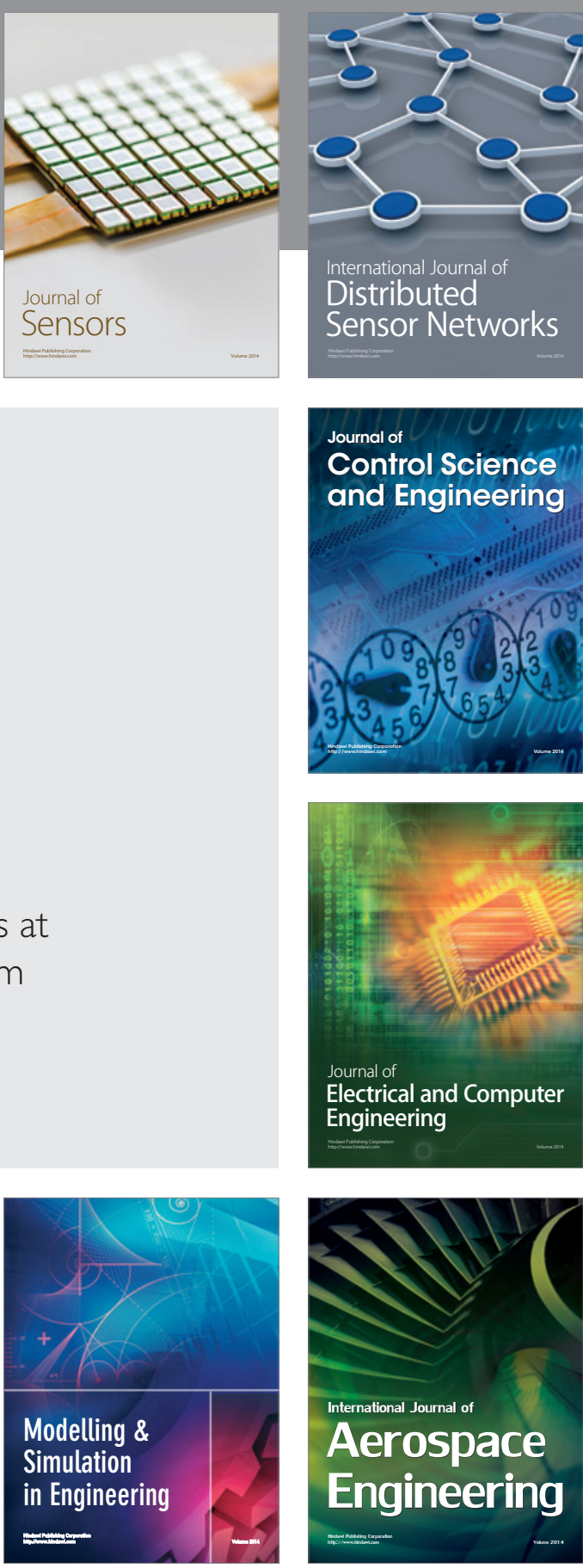

International Journal of

Distributed

Sensor Networks

Journal of

Control Science

and Engineering
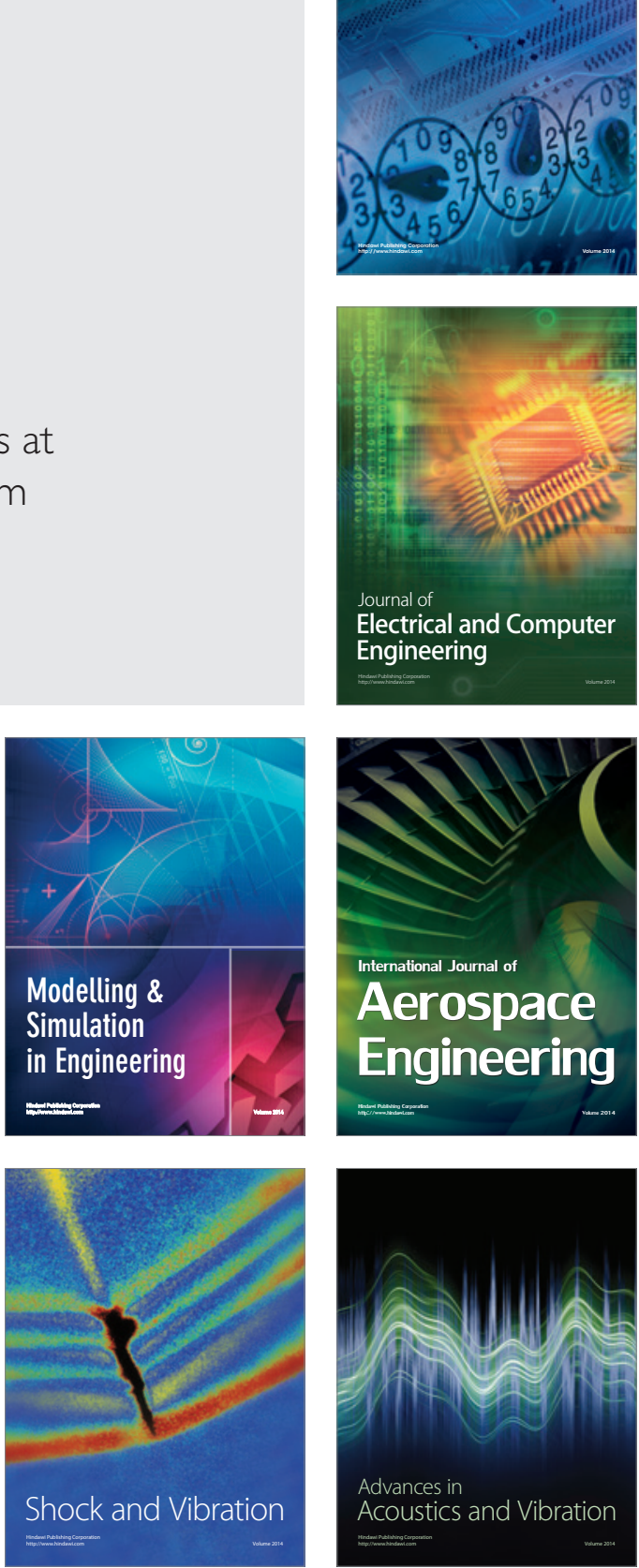